\title{
Intratracheal atomized surfactant provides similar outcomes as bolus surfactant in preterm lambs with respiratory distress syndrome
}

\author{
Ilaria Milesi', David G. Tingay ${ }^{2,3,4}$, Emanuela Zannin' ${ }^{1}$, Federico Bianco ${ }^{5}$, Paolo Tagliabue ${ }^{6}$, Fabio Mosca ${ }^{7}$, Anna Lavizzari ${ }^{7}$, \\ Maria Luisa Ventura ${ }^{6}$, C. Elroy Zonneveld ${ }^{2}$, Elizabeth J. Perkins ${ }^{2}$, Don Black ${ }^{2}$, Magdy Sourial ${ }^{2}$ and Raffaele L. Dellacá
}

BACKGROUND: Aerosolization of exogenous surfactant remains a challenge. This study is aimed to evaluate the efficacy of atomized poractant alfa (Curosurf) administered with a novel atomizer in preterm lambs with respiratory distress syndrome.

METHODS: Twenty anaesthetized lambs, $127 \pm 1 \mathrm{~d}$ gestational age, (mean \pm SD) were instrumented before birth and randomized to receive either (i) positive pressure ventilation without surfactant (Control group), (ii) $200 \mathrm{mg} / \mathrm{kg}$ of bolus instilled surfactant (Bolus group) at 10 min of life or (iii) $200 \mathrm{mg} / \mathrm{kg}$ of atomized surfactant (Atomizer group) over $60 \mathrm{~min}$ from $10 \mathrm{~min}$ of life. All lambs were ventilated for $180 \mathrm{~min}$ with a standardized protocol. Lung mechanics, regional lung compliance (electrical impedance tomography), and carotid blood flow (CBF) were measured with arterial blood gas analysis.

RESULTS: Dynamic compliance and oxygenation responses were similar in the Bolus and Atomizer groups, and both better than Control by 180 min (all $P<0.05$; two-way ANOVA). Both surfactant groups demonstrated more homogeneous regional lung compliance throughout the study period. There were no differences in CBF

CONCLUSION: In a preterm lamb model, atomized surfactant resulted in similar gas exchange and mechanics as bolus administration. This study suggests evaluation of supraglottic atomization with this system when noninvasive support is warranted.

S urfactant replacement therapy is a well-established standard of care for the treatment and prevention of neonatal respiratory distress syndrome (RDS), significantly reducing mortality and morbidity (1). Currently, endotracheal instillation is the only approved method of administration. However, over the last decade, the management of mild to moderate RDS has dramatically changed, endotracheal tube (ETT) intubation is often avoided and infants were managed with noninvasive modalities, such as continuous positive airway pressure whilst spontaneously breathing. In this population, surfactant administration is generally only provided when oxygen requirement increases and intubation is necessary $(2,3)$.

The increase in noninvasive ventilation use has led to less invasive methods of surfactant delivery during continuous positive airway pressure being developed $(4,5)$. All reported methods require technical skills, some degree of invasive intervention, and still involve instillation of liquid surfactant directly into the trachea via a process that is not dissimilar to intubation (6-8). Nebulization of surfactant offers an attractive alternative. Unfortunately, studies of nebulized surfactant have shown inconsistent clinical response and surfactant distribution (9-16). Moreover, most of the studies, even those in which a lung function improvement was observed, reported very low $(<10 \%)$ fractions of surfactant deposition into the lung $(9,12,17-20)$. Notwithstanding differences in nebulizer design, and thus particle size production, such modest deposition is likely due to the fact that most studies used aerosols generated extracorporeally by nebulizers connected to the ventilator circuit. This leads to high amounts of surfactant loss in the circuit, environment, and upper airway mucosa rather than the intended deep lung deposition.

An alternative approach, using special catheters designed for intracorporeal surfactant nebulization has been proposed $(8,21)$. Intratracheal nebulization of surfactant using this method has been shown to provide equivalent oxygen response as standard bolus therapy $(8,21)$, with high and even surfactant deposition (21), improved histological score, and less cerebral hemodynamics fluctuations in adult rabbits (21) and preterm lambs (8) with severe induced RDS. These two studies have shown the efficacy of intratracheal aerosolization of surfactant in two very severe models of RDS, surfactantdepleted adult rabbits, and preterm lambs with severe surfactant deficiency. Nevertheless, in these studies the animals were managed with intensive mechanical ventilation and paralysis,

\footnotetext{
The first two authors share first authorship.

'Dipartimento di Elettronica, Informazione e Bioingegneria, Politecnico di Milano University, Milano, Italy; ${ }^{2}$ Neonatal Research, Murdoch Childrens Research Institute,

Melbourne, Australia; ${ }^{3}$ Neonatology, The Royal Children's Hospital, Parkville, Australia; ${ }^{4}$ Department of Paediatrics, University of Melbourne, Melbourne, Australia; ${ }^{5}$ Research and Development Department, Chiesi Farmaceutici SpA, Parma, Italy; ${ }^{6}$ Neonatal Intensive Care Unit, Fondazione MBBM, Monza, Italy; ${ }^{7} \mathrm{NICU}$, Fondazione IRCCS Ca' Granda, Ospedale Maggiore Policlinico-Università degli Studi di Milano. Correspondence: Ilaria Milesi (ilaria.milesi@polimi.it)

Received 7 August 2015; accepted 21 December 2015; advance online publication 30 March 2016. doi:10.1038/pr.2016.39
} 
while in clinical practice the babies that may benefit most from surfactant atomization would be those that can be managed with a less intensive respiratory support strategy.

Recently, we developed a novel atomizing system for intracorporal atomization of surfactant into the supraglottic space during continuous positive airway pressure (22). This system consists of a small multilumen catheter whose tip can be placed in the supraglottis region bypassing the upper airways and directly atomizing into the pharynx, avoiding the need for intubation. The device also synchronizes delivery to inspiration, offering more effective delivery.

The aim of this proof of concept study was to evaluate the efficacy of this new device. Specifically, we aimed to compare the effect of surfactant delivered via atomization with standard

Table 1. Study group characteristics

\begin{tabular}{lccccc}
\hline & $\begin{array}{c}\text { Weight } \\
(\mathrm{kg})\end{array}$ & F:M & $\begin{array}{c}\text { Singleton } \\
(n)\end{array}$ & Cord $\mathrm{pH}$ & $\begin{array}{c}\text { Lung weight } \\
(\mathrm{g} / \mathrm{kg})\end{array}$ \\
\hline Atomizer $(n=7)$ & $3.84 \pm 0.45$ & $4: 3$ & 2 & $7.35 \pm 0.06$ & $29.7 \pm 3.8$ \\
Bolus $(n=6)$ & $3.06 \pm 0.42$ & $6: 0$ & 0 & $7.35 \pm 0.05$ & $32.0 \pm 3.5$ \\
Control $(n=8)^{\mathrm{a}}$ & $2.94 \pm 0.78^{*}$ & $6: 1$ & 2 & $7.36 \pm 0.09$ & $30.1 \pm 6.1$
\end{tabular}

Data reported as mean \pm SD. F:M, number of female vs. male lambs. Lung weight (g/kg) was normalized for body weight.

ane lamb excluded due to pneumothorax. ${ }^{*} P<0.05$ (two-way ANOVA) Atomizer vs. Control.

a

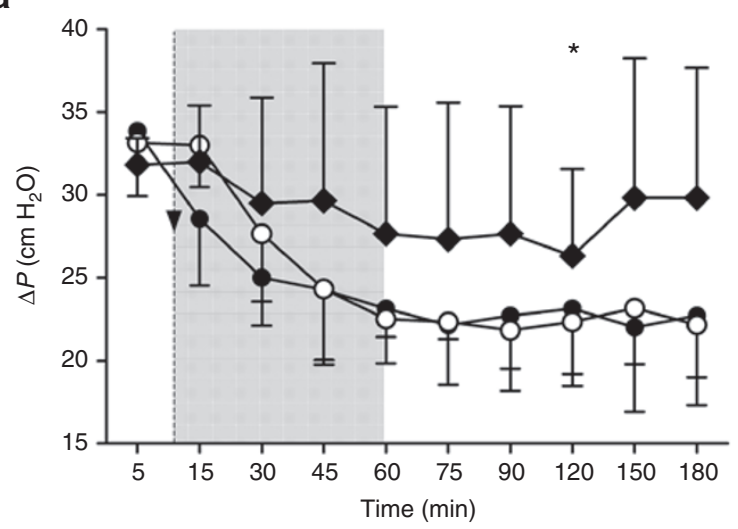

b

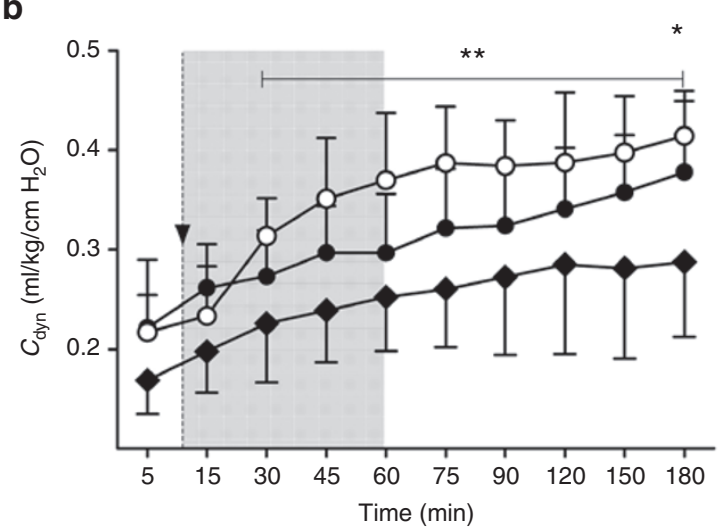

bolus instillation on gas exchange, lung mechanics, and homogeneity of lung compliance in preterm lambs with a mildmoderate model of RDS.

\section{RESULTS}

Table 1 summarizes the baseline characteristics of each group. All lambs completed their assigned protocol without complications, except one lamb (Control) that developed a pneumothorax and was excluded. There were no statistically significant differences in lung weight, fetal $\mathrm{pH}$, fraction of inspired oxygen or $\mathrm{PaO}_{2}$ at $5 \mathrm{~min}$ of life. There was a trend toward more male and heavier lambs in the Atomizer group. The median (interquartile range, IQR) duration of atomization was 53 (48-56) min, being determined by the atomized volume of surfactant $(9.60 \pm 1.15 \mathrm{ml}$; mean $\pm \mathrm{SD})$. Surfactant delivery was well tolerated without any adverse events.

Pressure swing $(\Delta P)$ was similar between all groups at $5 \mathrm{~min}$. Thereafter, all groups showed a time-based improvement (Figure 1a). Compared with baseline, the two surfactant groups showed a statistically and clinically relevant reduction in $\Delta P$ with time compared with Control (Figure 1c, $P<0.05$ at $45,75,90,150$, and $180 \mathrm{~min})$. Dynamic compliance $\left(C_{d y n}\right)$ was higher in the two surfactant groups compared with Control at $5 \mathrm{~min}$, but this was not significant $(P=\mathrm{NS}$; Holm-Sidak post-test); Figure 1b. All groups showed a

C

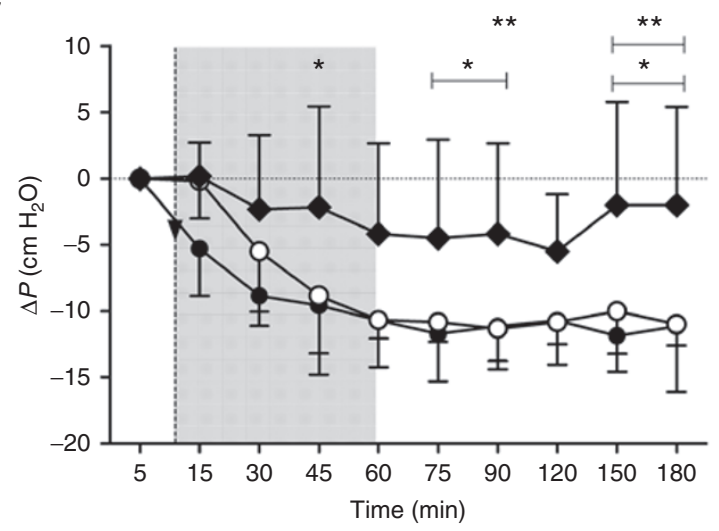

d

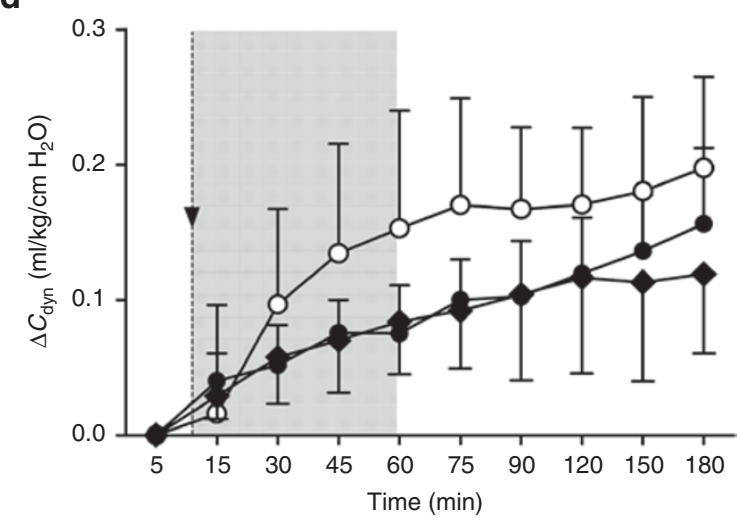

Figure 1. Lung mechanics. Pressure swing (a), $C_{\mathrm{dyn}}$ (b), and change in pressure swing (c) and $C_{\mathrm{dyn}}$ from initial value (d) during the 180-min study period for the Atomizer (closed circles-solid line), Bolus (open circles-solid line), and Control (closed diamonds-solid line) groups. Grey area: surfactant atomization; arrow: bolus instillation. Data mean and SD. ${ }^{*} P<0.05$ Atomizer vs. Control, ${ }^{* *} P<0.05$ Bolus vs. Control (all $P$ values Holm-Sidak post-tests). $C_{\text {dyn' }}$ dynamic compliance. 


\section{Articles | Milesiet al.}

similar time-based improvement in $C_{\text {dyn }}(P<0.0001$ two-way ANOVA). Administration of surfactant improved $C_{\text {dyn }}(P<$ 0.01 at $\min 180$ vs. $5 \mathrm{~min}$ ) with no significant difference at 180 min between surfactant therapy groups, and with both surfactant groups demonstrating higher $C_{\text {dyn }}$ compared with the Control group $(P<0.0001$, Figure $1 b)$, although there was no significantly difference in the change in $C_{\mathrm{dyn}}$ from baseline values between groups at $180 \mathrm{~min}$ (Figure 1d).

The oxygenation index (OI) increased with time in the Control group (Figure 2a,d) and was significantly higher than baseline $(5 \mathrm{~min})$ values by $90 \mathrm{~min}(P<0.01$, Holm-Sidak posttests). In contrast, there was no temporal change in OI within the Bolus and Atomizer groups; being significantly lower than Control from $60 \mathrm{~min}$ in the Atomizer $(P<0.05)$ and $45 \mathrm{~min}$ in the Bolus $(P<0.01)$ groups. There was no difference in both arterial partial pressure of carbon dioxide $\left(\mathrm{PaCO}_{2}\right)$ and changes in $\mathrm{PaCO}_{2}$ with time between the two surfactant groups (both were lower than Control at all time points, Figure 2c,e). A modified ventilation efficiency index, modified to account for the fact that tidal volume was adjusted to target $\mathrm{PaCO}_{2}$, was significantly lower in the Control group compared with Atomizer, but not in Bolus, from $15 \mathrm{~min}$ of life (Figure 2e) with all groups showing similar variations with time (Figure 2f).

There were no differences in heart rate and mean arterial pressure between groups (Table 2). The Bolus group had a transient fall in mean arterial pressure immediately after surfactant delivery $(15 \mathrm{~min})$ compared with $5 \mathrm{~min}$ of life $(P<0.05$; Holm-Sidak post-test). Mean arterial pressure was lower in the Atomizer group at 60 and $180 \mathrm{~min}$ compared with $5 \mathrm{~min}(P<0.05)$. Mean carotid blood flow (CBF) was stable in all groups over time, including during the administration of surfactant.

Figures 3 and 4 show the relative regional gravity-dependent distribution of $C_{\text {dyn }}$ at 5 and 180 min of life measured by electrical impedance tomography (EIT). This method provides visual representation of the pattern of dynamic compliance distribution within the lung. Gravity-dependent regional $C_{\mathrm{dyn}}$ was uniform across the two study periods for the surfactant-treated groups, demonstrating relatively homogeneous spatiotemporal
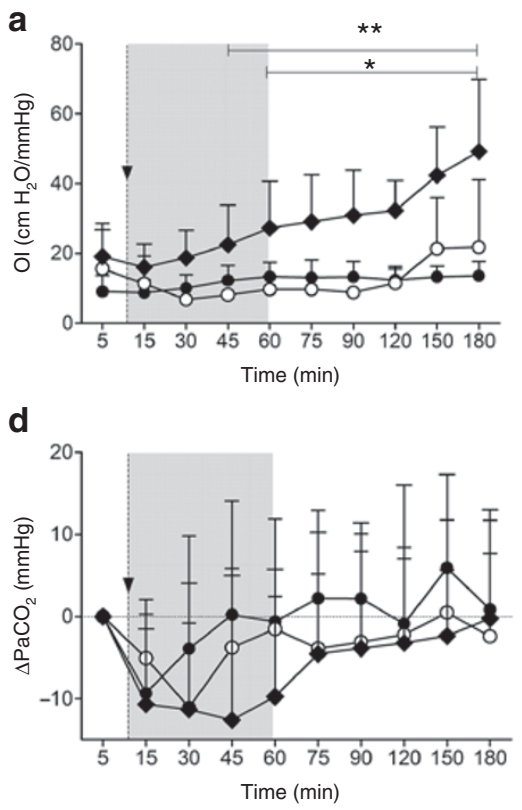

b

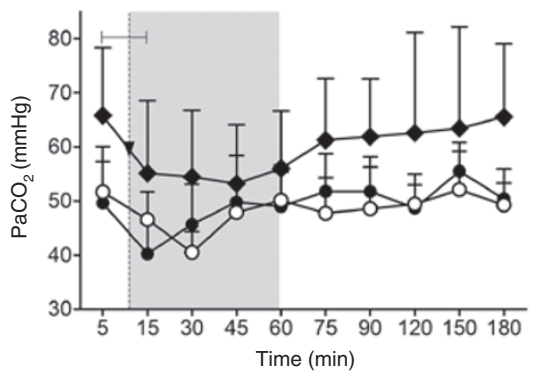

e

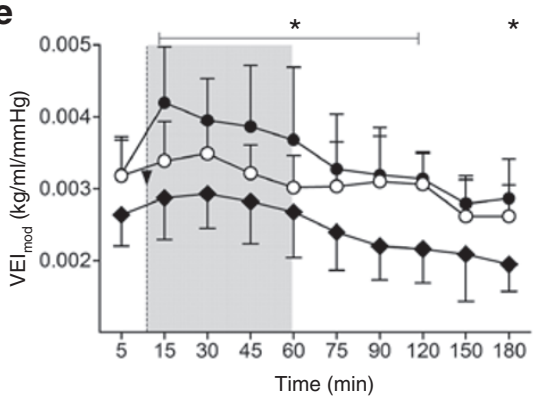

C

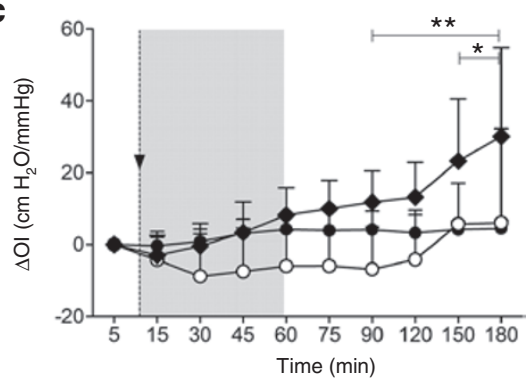

f

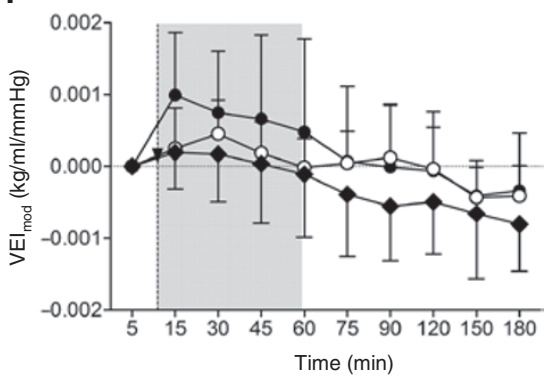

Figure 2. Gas exchange (a) $\mathrm{OI}$, (b) $\mathrm{PaCO}_{2}$ (c) $\mathrm{VEI}_{\text {mod' }}$ (d) $\Delta \mathrm{OI}$, (e) $\Delta \mathrm{PaCO}_{2^{\prime}}$ (f) $\Delta \mathrm{VEI}_{\text {mod }}$. Data expressed as mean and SD. * $\mathrm{P}<0.05$ Atomizer vs. Control, ${ }^{* *} P<0.05$ Bolus vs. Control (Holm-Sidak post-tests). Ol, oxygenation index; $\mathrm{VEI}_{\text {mod' }^{\prime}}$ modified ventilation efficiency index.

Table 2. Hemodynamic results

\begin{tabular}{|c|c|c|c|c|c|c|c|c|c|}
\hline \multirow{2}{*}{$\begin{array}{l}\text { Time } \\
(\mathrm{min})\end{array}$} & \multicolumn{3}{|c|}{$\mathrm{HR}(\mathrm{bpm})$} & \multicolumn{3}{|c|}{$\mathrm{MAP}(\mathrm{mmHg})$} & \multicolumn{3}{|c|}{ Mean CBF (mL/min/kg) } \\
\hline & Atomizer & Bolus & Control & Atomizer & Bolus & Control & Atomizer & Bolus & Control \\
\hline 5 & $147 \pm 35$ & $131 \pm 46$ & $183 \pm 46$ & $44 \pm 10$ & $44 \pm 10$ & $47 \pm 8$ & $N A^{a}$ & $N A^{a}$ & $N A^{a}$ \\
\hline 60 & $153 \pm 20$ & $161 \pm 21$ & $160 \pm 37$ & $32 \pm 3^{* *}$ & $37 \pm 9$ & $40 \pm 12$ & $17.0 \pm 9.6$ & $12.0 \pm 11.6$ & $12.6 \pm 5.8$ \\
\hline 120 & $142 \pm 14$ & $163 \pm 45$ & $158 \pm 38$ & $34 \pm 5$ & $41 \pm 18$ & $40 \pm 13$ & $15.8 \pm 9.3$ & $14.8 \pm 13.0$ & $12.6 \pm 7.2$ \\
\hline
\end{tabular}

Data reported as mean $\pm \mathrm{SD}$.

$\mathrm{CBF}$, mean carotid blood flow; HR, heart rate; MAP, mean arterial pressure.

a Mean CBF at 5 min is not available (NA) because data were not reliable in some lambs due to probe movement during delivery. ${ }^{*} P<0.05$ vs. 5 min within Control group, ${ }^{* *} P<0.05$ vs.

5 min within Atomizer group, ${ }^{\dagger} P<0.05$ vs. 5 min within Bolus group, Holm-Sidak post-test. 
a

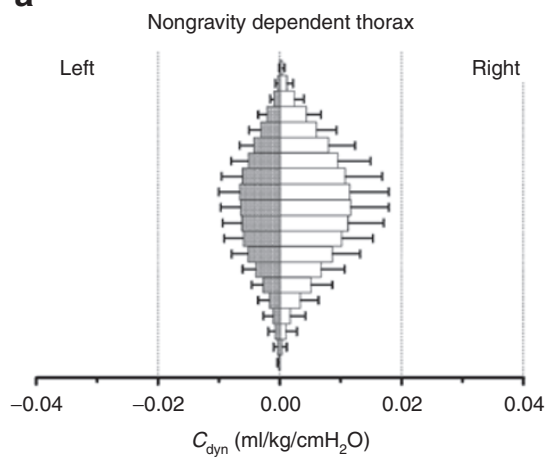

d

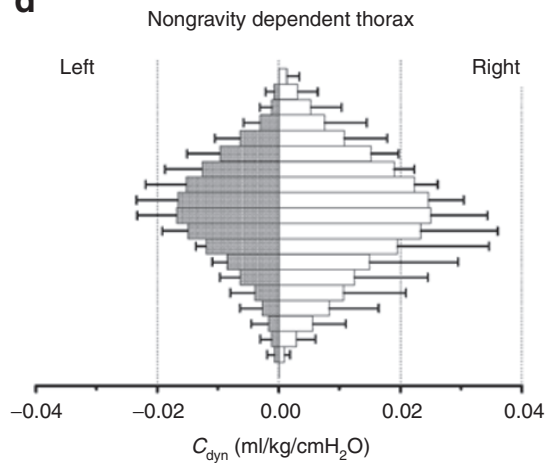

b

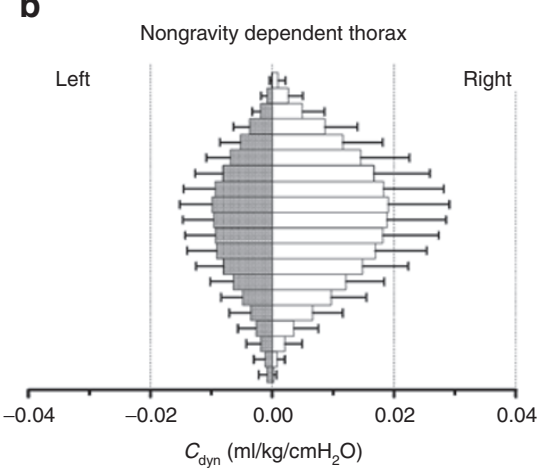

e

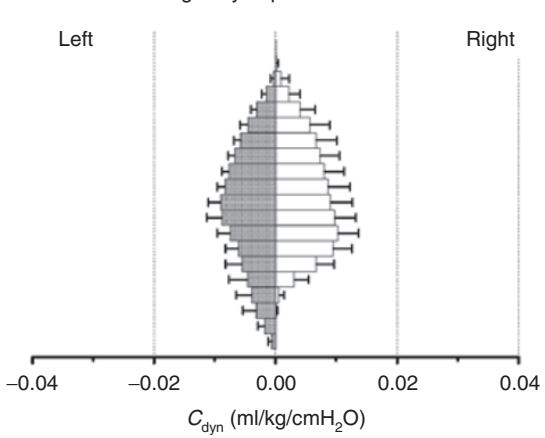

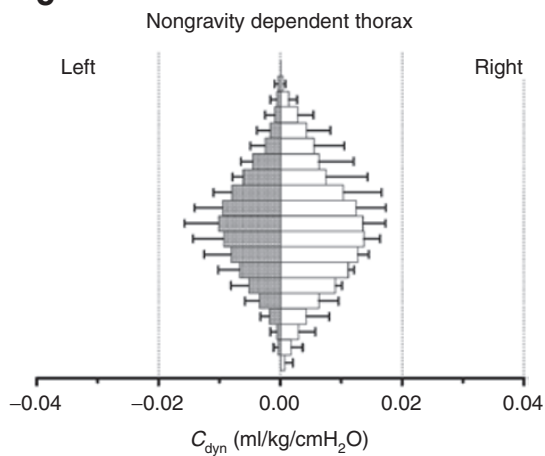

f

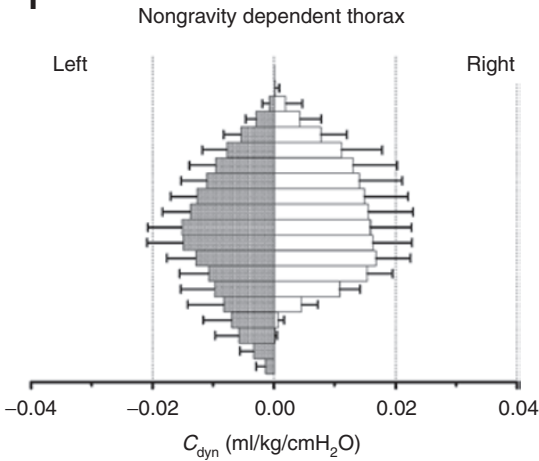

Figure 3. Regional lung compliance. Functional EIT images of the relative regional gravity-dependent distribution of $\mathrm{C}_{\mathrm{dyn}}$ (expressed in $\mathrm{mL} / \mathrm{cm}_{2} \mathrm{O} / \mathrm{kg}$ ) in the Atomizer, Bolus, and Control groups at 5 and $180 \mathrm{~min}$ in each of the 20 lung tissue containing slices for the right (white bars) and left (grey bars) hemithoraces. The images are orientated such that the most gravity nondependent (ventral) lung is orientated at the top of each bar graph, and the most dependent (dorsal) regions at the bottom using the method of Frerichs and co-workers (25). Atomizer at $5 \mathrm{~min}$ (a) and $180 \mathrm{~min}$ (b), Bolus at 5 min (c) and $180 \mathrm{~min}(\mathbf{d})$, and Control at $5 \mathrm{~min}(\mathbf{e})$ and $180 \mathrm{~min}(\mathbf{f}) . C_{\mathrm{dyn}}$ dynamic compliance; EIT, electrical impedance tomography.

a

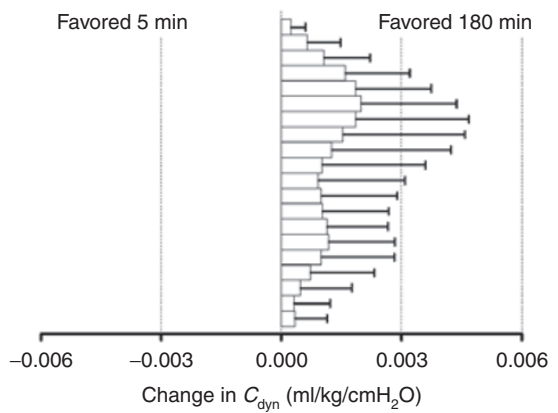

b

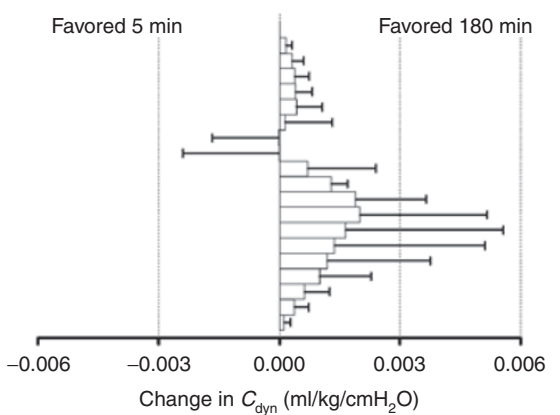

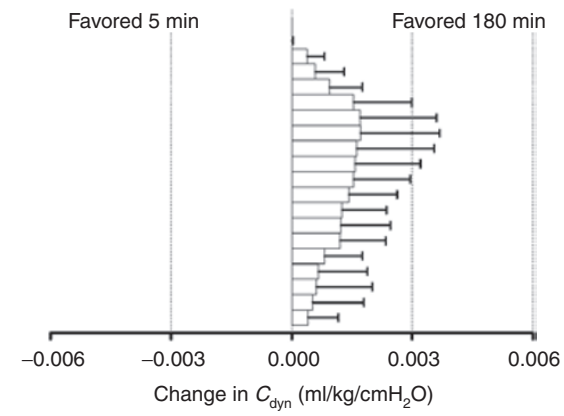

Figure 4. Variation in regional lung compliance. Change in gravity-dependent distribution of $C_{\text {dyn }}$ throughout the lung between 5 and 180 min, using subtraction histograms to express the difference in $C_{\text {dyn }}$ within each lung region between 5 and 180 min using the same gravity-dependent orientation as Figure 3. Atomizer group: $180 \mathrm{~min}$ vs. $5 \mathrm{~min}$ (a), Bolus group: $180 \mathrm{~min}$ vs. $5 \mathrm{~min}$ (b) and Control group: $180 \mathrm{~min}$ vs. $5 \mathrm{~min}$ (c). Data to the right indicates $C_{\text {dyn }}$ was better at 180 than at $5 \mathrm{~min}$ within that region of interest, and vice versa. All data are mean and SD. $C_{\text {dyn' }}$ dynamic compliance.

improvement by $180 \mathrm{~min}$. In contrast, the control group had an inhomogeneous gravity-dependent pattern of $C_{\mathrm{dyn}}$ at $5 \mathrm{~min}$, with marked reduction in the right-dependent regions. This spatial inhomogeneity increased during the study period.

\section{DISCUSSION}

In our intubated preterm lamb model of moderate RDS, we demonstrated that surfactant delivered via our novel atomization technique had an equivalent effect on lung mechanics and gas exchange as bolus surfactant administration. Importantly, both methods were better than mechanical ventilation without surfactant. These data suggest that atomization of surfactant may be an effective method of surfactant delivery to the lung in spontaneously breathing recipients if a feasible method of supraglottic delivery can be achieved.

Both methods of surfactant administration (bolus and atomization) had a similar positive effect on $\Delta P$ and OI. Bolus administration, the current clinical standard, achieved a rapid change in $C_{\text {dyn }}$ after administration, whilst this was achieved more gradually with atomization. This pharmacodynamic 


\section{Articles | Milesietal.}

effect is not unexpected due to the longer delivery times. The short study duration after completing the atomization period may not have been sufficient to allow the full post surfactant effect to have occurred, as evident by the ongoing increase in $\Delta C_{\text {dyn }}$.

Delivery was dose-related, and lambs have a higher birth weight than preterm human infants, suggesting quicker delivery in the latter population. The slower effect of atomization is not necessarily a limitation of this approach. It may reduce the potential of rapid changes in $\mathrm{PaO}_{2}$ and $\mathrm{PaCO}_{2}$ (8). In addition, atomized surfactant therapy is intended for infants receiving noninvasive ventilation, who are likely to have a milder form of RDS than intubated infants.

$C_{\text {dyn }}$ assesses total lung compliance, but we also used functional EIT to evaluate the effect of different modalities of surfactant administration on ventilation distribution and regional changes in dynamic compliance. Despite the well-described limitations (23), EIT provides the only clinical translatable method of regional lung imaging, and has been used previously to describe the changes in the lung during surfactant administration (24). Importantly, EIT offers the ability to image multiple volume state parameters, including regional ventilation (24) and $C_{\text {dyn }}(25,26)$. RDS is a disease characterized by regional heterogeneity of ventilation. Approaches that rectify heterogeneity are essential components of lung protective ventilation strategies $(27,28)$. The ability of bolus surfactant therapy to reduce ventilation heterogeneity has been validated using EIT in animals (24) and humans (29), and our Bolus group data were similar. Both surfactant administration strategies resulted in more homogenous spatial gravity-dependent patterns of regional $C_{\mathrm{dyn}}$ over time consistent with the global mechanical and oxygenation outcomes. Although we did not undertake formal deposition analysis, the EIT results suggest similar distribution of surfactant, at least functionally. The Control group had more regional gravity-dependent heterogeneity of $C_{\mathrm{dyn}}$ at baseline, and this pattern did not change despite the time-dependent improvement in global $C_{\text {dyn }}$, indeed heterogeneity increased with time.

Interestingly, $\mathrm{CBF}$ remained stable in all groups during the study, specifically during and after surfactant treatment. Bolus surfactant therapy has been associated with rapid fluctuations in cerebral blood flow (8). It is possible that the relative respiratory stability of our lamb model and the use of sedatives and analgesia provided resilience to the interruption in mechanical ventilation during bolus delivery. Compared with other studies (8), we did not observe a dramatic change in $\mathrm{PaCO}_{2}$, which may have contributed to stable $\mathrm{CBF}$. The instrumentation of the carotid arteries may also have influenced the CBF data, although any effect would be standardized across all lambs. We also only recorded flow in one of the many vessels supporting cerebral perfusion, and it is possible that total cerebral blood flow was different and other techniques such as near-infrared spectroscopy may yield different results.

Tolerance of the atomizing catheter and process during administration will be major contributors to clinical feasibility. Our lambs were intubated, not exposed to antenatal steroids and had spontaneous breathing effort suppressed, unlikely events for the intended clinical situation, and also confounders in assessing tolerance. These interventions were intentional to ensure that the interaction between modes of surfactant delivery was not influenced by other variables such as site of delivery and potential differences due to spontaneous respiratory effort.

During the atomization period, the Atomizer group did have a nonsignificant trend toward a higher modified ventilation efficiency index from 15 to 60 min of life compared with the Bolus group. This difference was likely associated to the atomization procedure, disappearing on completion. In our opinion, this effect may be related to the washout of the dead space due by the intratracheal injection of the atomizing gas with a mechanism similar to that already reported during high-flow nasal cannulae (30-32).

Our study is not the first to describe intratracheal administration of nebulized surfactant. In surfactant-depleted adult rabbits, Wagner and co-workers (21) demonstrated that a surfactant fog delivered via the ETT improved $\mathrm{PaO}_{2}$ and $\mathrm{PaCO}_{2}$ similarly to bolus instillation with better distribution and intrapulmonary recovery rates of approximately $86.5 \%$. ReySantano and co-workers (8) showed similar gas exchange and lung mechanics to bolus surfactant, with lower lung injury and less cerebral hemodynamics fluctuations, following intratracheal administration of aerosolized surfactant $(<5 \mu \mathrm{m})$ in preterm lambs with severe RDS in whom noninvasive ventilation would be unlikely. We contend that our lamb model was more representative of most preterm infants with acute RDS in the modern era. To date no clinical devices for the delivery of nebulized surfactant in combination with noninvasive respiratory support have proved to be effective.

The treatment of preterm neonates with nebulized surfactant is challenging, due to the low inspiratory flows, high respiratory rates, and small airways that characterize the preterm lung, and generally high viscosity of most of the surfactants (33). Despite many experimental studies of nebulized surfactant, using various animal models of surfactant deficiency or depletion, the results have been inconsistent and often disappointing. In some studies, there was no benefit from nebulized surfactant $(10,12,13)$, whereas in others a significant improvement in gas exchange and lung mechanics was observed $(9,11)$. A possible explanation of these findings is the low rates of surfactant deposition within the lung. Most previous nebulization methods $(9,12,17-20)$ have been based on a extracorporeal delivery mechanism, often within the ventilator circuit. This will result in significant deposition within the circuit and upper respiratory system. High-yield deposition within the deep lung will be fundamental to the clinical success, and uptake of any nebulization system for surfactant.

Our system was specifically designed to minimize surfactant loss prior to the deep lung, using intracorporeal administration below the upper airways, synchronization to inspiration and generating relatively big particles. Even though the subglottic location of the catheter within our experimental design may have contributed to increased deposition of surfactant 
in the deep lung, we expect that good deposition can also be achieved by placing the catheter above the vocal folds. This would necessitate some changes to the whole system from our surrender system to optimize the placement of the atomizing catheter. Moreover, we used synchronization with inspiration with the rationale of reducing the surfactant dose required and minimizing the risk of surfactant pooling within the pharynx during spontaneous breathing, as the atomized particles are expected to be transported by inspiratory flow in the trachea.

Another important difference in our atomization system from many other studies was particle size generation. We designed our system to deliver relatively large particles (median $91 \mu \mathrm{m}$ ), because we speculated that larger particle size would minimize surfactant loss during expiration and facilitate better distribution to nonventilated lung regions via diffusion gradients, the spreading properties of surfactant, the Marangoni effect, and capillarity compared with small particles. In fact, although many previous studies have suggested that particles of $<5 \mu \mathrm{m}$ are needed for homogeneous deposition and penetration of the distal air spaces (34), we contend that small particles, being driven by inspired airflow, may reach only those alveoli that are already open. As a partial support of this theory, a recent small human trial of nebulized surfactant with $2.5-\mu \mathrm{m}$ particles did not show a significant difference in outcomes compared with continuous positive airway pressure alone (15). As a consequence we aimed for particles that were large but also not too big to be detrimentally influenced by gravity. Even though we did not measure surfactant deposition, the similarities in outcomes compared with bolus delivery, and difference from control, suggest a reasonable fraction of surfactant was delivered to the deep lung using our system. This justifies further studies during noninvasive support and spontaneous breathing.

Finally, in designing our device, we targeted a delivery time of approximately $20 \mathrm{~min}$ for preterm infants to guarantee the tolerance of the atomizing catheter, and to achieve clinical efficacy in a relatively short time period. As discussed previously, in this study the 60-min atomization period was due to the weight of the lambs, which were more than three times heavier than a preterm infant.

\section{Limitations of the Study}

This study has some limitations not already mentioned. Although we tried to limit differences in lung immaturity and standardized the gestational age, we observed variability in the severity of RDS among animals, specifically in the groups at baseline, that may have led to differences in the response to surfactant treatment. The Atomizer group was heavier at birth, which may have been beneficial, although this group also had less female lambs. Predicting birth weight during fetal instrumentation is difficult and it was our intention to randomize interventions. The control group had worse baseline gas exchange, lung mechanics, and regional ventilation than the other two groups prior to any surfactant therapy. This suggests that the differences seen at study end may not have been related to surfactant therapy but could have been due to respiratory transition. We contend that the rate of change in OI and $C_{\mathrm{dyn}}$ after surfactant therapy makes it unlikely that there was not some treatment response influencing the differences in outcome. As this study was a proof-of-principle study, and bolus surfactant is well established as a method of reducing lung injury in RDS, we did not undertake injury analysis. Future studies in spontaneously breathing recipients should consider deposition and injury end points.

\section{Conclusion}

In our preterm lamb model of moderate RDS, intratracheal atomized surfactant via a novel atomization system had a similar influence on regional lung mechanics and gas exchange as bolus administration. This point-of-concept study suggests that atomization of surfactant if feasible and likely results in lung deposition. Further studies in spontaneously breathing subjects receiving noninvasive ventilation using a supraglottic administration technique are warranted.

\section{METHODS}

The study was performed at the Murdoch Children's Research Institute, Melbourne, Australia and approved by the Institution's Animal Ethics Committee. Animals were cared for in accordance with the guidelines of the National Health and Medical Research Council of Australia.

\section{Animal Preparation}

Border-Leicester/Suffolk lambs $(n=20)$ were studied at $127 \pm 1 \mathrm{~d}$ of gestation (term $\sim 145 \mathrm{~d}$ ). Lambs were delivered by caesarean section to ewes receiving isoflurane and nitrous-oxide inhalational anaesthesia, after premedication with xylazine $2 \mathrm{mg}$ IM and ketamine $150 \mathrm{mg}$ IM. Antenatal corticosteroids were not administered to increase the degree of RDS in this short-term study. Whilst on placental support, the carotid artery and external jugular vein were cannulated. The other carotid artery was encircled with a 4-mm transit-time flow probe (Transonic Systems, Ithaca, NY). Animals were tracheotomized and intubated using a $4.5-\mathrm{mm}$ internal diameter cuffed ETT (Atomizer group) or a $4.0-\mathrm{mm}$ tube (other groups), with approximately similar internal diameters after inserting the atomizer catheter. Fetal lung liquid was passively drained prior to delivery and the ETT clamped. The fetal thorax was then exteriorized and dried. Sixteen custom-built EIT electrodes were placed equidistant around the fetal chest using our previously described methodology $(35,36)$. The EIT electrodes were connected to a Goe-MF II EIT system (CareFusion, Hoechberg, Germany), and a 10-s baseline recording of the unaerated lung made as a reference. If the lamb was allocated to receive atomized surfactant a custom-built catheter system was introduced into the ETT via a Ballard closed suction ETT adaptor (Kimberly-Clark, Neenah, WI). At delivery, the umbilical cord was cut, the lamb weighed and placed supine before starting mechanical ventilation. Analgesia and anaesthesia were maintained throughout with midazolam and ketamine infusions titrated to suppress spontaneous breathing. Hydration was achieved with a $0.18 \% \mathrm{NaCl}$ and $4 \%$ glucose intravenous infusions.

\section{Study Design}

Prior to birth, animals were randomly allocated to one of the following groups:

Control group $(n=8)$.

Animals, who did not receive surfactant.

Bolus group $(n=6)$.

Animals that received $200 \mathrm{mg} / \mathrm{kg}$ of poractant alfa surfactant (Curosurf; Chiesi Farmaceutici, Parma, Italy) at $10 \mathrm{~min}$ of life as a single bolus administered over $10-15 \mathrm{~s}$ via a 6 -FG (French Gauge) feeding catheter, premeasured to the ETT tip, and a closed system (NeoLink, Carefusion, San Diego, CA). 


\section{Articles $\mid$ Milesiet al.}

\section{Atomizer group $(n=7)$.}

Group of animals, in which $200 \mathrm{mg} / \mathrm{kg}$ of poractant alfa surfactant was atomized over a $60-\mathrm{min}$ period from $10 \mathrm{~min}$ of life.

All lambs were ventilated for $180 \mathrm{~min}$, using a standardized protocol detailed below, to allow observation of time-based changes in regional ventilation and mechanics for at least $120 \mathrm{~min}$ after completing surfactant administration.

\section{Experimental Set-up}

The experimental set-up is schematically reported in Figure 5. Peripheral oxygen saturation, heart rate, arterial blood pressure (HP48S monitor, Hewlett Packard, Andover, MA), and CBF were recorded continuously from birth. Pressure $\left(P_{\mathrm{aa}}\right)$ and flow $\left(V_{\mathrm{ao}}^{\prime}\right)$ were measured at the airway opening using a Florian respiratory mechanics monitor (Acutronic Medical Systems, Hirzel, Switzerland). All signals were sampled at $1,000 \mathrm{~Hz}$ and acquired using a Powerlab/ Lab Chart system (Version 7, AD Instruments, Sydney, Australia). Relative changes in regional thoracic volume were measured using the Thorascan software package sampling at $25 \mathrm{~Hz}(37,38)$. Arterial blood gas analysis was performed at 5, 10, and $15 \mathrm{~min}$ of life, and then 15 -minutely until 90 min life and then 30 -minutely until completion of the study.

Atomized surfactant was delivered using an ad hoc system (22). Briefly, the system was composed of an atomizing catheter connected to a modified infusion pump, delivering surfactant at a rate of $0.4 \mathrm{ml} /$ min, triggered to the pressure signal recorded at the airway opening, such that surfactant was only delivered during inspiration. The characteristics of Curosurf after atomization with our catheters were defined before the study. Specifically, particles size was measured using the laser diffraction method (Spraytech, Malvern Instruments,Malvern, UK) and retention of physiochemical properties confirmed in vivo in preterm rabbits. The atomizing catheters are made of a central lumen, through which the surfactant flows and several outer lumens in which atomizing gas (compressed air) flows at a rate of $0.7 \mathrm{l} / \mathrm{min}$. At the tip of the catheter, high-velocity air breaks the liquid jet producing particles with a median (10th-90th percentile) of $91(27-197) \mu \mathrm{m}$. The atomization catheter was kept centred in the ETT by a custom-built fine wire support to avoid spraying surfactant toward the ETT walls whilst not interrupting ventilator gas flow.

\section{Ventilation Strategy}

Mechanical ventilation was applied using positive pressure ventilation in a targeted tidal volume mode (SLE5000 infant ventilator, SLE, South Croydon, UK). Initially, tidal volume $\left(V_{\mathrm{T}}\right)$ was set at $7.0 \mathrm{ml} / \mathrm{kg}$, maximum positive inspiratory pressure at $40 \mathrm{~cm} \mathrm{H}_{2} \mathrm{O}$, positive end-expiratory pressure at $8 \mathrm{~cm} \mathrm{H}_{2} \mathrm{O}$, respiratory rate at 60 $\mathrm{bpm}$, inspiratory time at $0.4 \mathrm{~s}$, and fraction of inspired oxygen at 0.3 . Thereafter, fraction of inspired oxygen was adjusted to maintain peripheral oxygen saturation between 88 and $94 \%$ and set $V_{\mathrm{T}}$ adjusted in increments of $1.0 \mathrm{ml} / \mathrm{kg}$ to maintain $\mathrm{PaCO}_{2}$ between 45 and 60 $\mathrm{mmHg}$. Maximum positive inspiratory pressure could be increased to a maximum of $50 \mathrm{~cm} \mathrm{H}_{2} \mathrm{O}$ if set $V_{\mathrm{T}}$ was not being met and $\mathrm{CO}_{2}$ clearance or oxygenation were compromised. Positive end-expiratory pressure was weaned (minimum of $6 \mathrm{~cm} \mathrm{H}_{2} \mathrm{O}$ ) if the lamb's respiratory status was improving following these measures.

At $180 \mathrm{~min}$, the lambs were humanely killed with a lethal dose of pentabarbitone and then exposed to atmosphere for $2 \mathrm{~min}$ to deflate the lung to functional residual capacity. A pressure-volume curve was performed using a calibrated glass super syringe from 0 to $40 \mathrm{~cm} \mathrm{H}_{2} \mathrm{O}$. This allowed calculation of the static mechanics of the lung and calibration of EIT (35,36,39-41).

\section{Data Analysis}

OI was determined at each arterial blood gas. A modified ventilation efficiency index was calculated to quantify $\mathrm{CO}_{2}$ exchange relative to magnitude of respiratory support, using the formula: $1 /\left(V_{\mathrm{T}}(\mathrm{ml} / \mathrm{kg})\right.$ $\left.\times \mathrm{PaCO}_{2}(\mathrm{mmHg})\right) . C_{\mathrm{dyn}}$ was computed from the $P_{\text {ao }}$ and $V^{\prime}$ data during five consecutive inflations using the least means squared algorithm (42). The mean CBF during each time period was determined from the CBF waveforms.

Regional changes in relative $C_{\mathrm{dyn}}$ were generated from the EIT data. For each lamb, the aerated EIT pixels at vital capacity were first determined to generate segmented lung image. Vital capacity was defined as the difference in impedance between 0 and $40 \mathrm{cmH}_{2} \mathrm{O}$ during the postmortem super-syringe pressure volume curve $(26,43)$. Functional EIT images of the pixels within the segmented regions were created from the tidal minimum to maximum impedance difference of the time-course signal (24). Functional EIT images were reconstructed from 20 to 30 inflations during each relevant time point that were free from artefact and containing stable $V_{\mathrm{T}}$ and pressure amplitudes. Functional EIT data were then calibrated to the average global $C_{\text {dyn }}$ value coinciding with the inflations $(40,44)$. Histograms of the gravity-dependent distribution of $C_{\mathrm{dyn}}$ in the right and left hemithorax were then generated $(25,26)$.

A sample size of six lambs per group was required to identify a difference in $C_{\text {drn }}$ of $0.1 \mathrm{ml} / \mathrm{cmH}_{2} \mathrm{O} / \mathrm{kg}$, assuming a SD of $0.05 \mathrm{ml} /$ $\mathrm{cmH}_{2} \mathrm{O} / \mathrm{kg}(8), 80 \%$ probability and an alpha error of 0.05 . All data were tested for normality and analyzed with an appropriate two-way ANOVA (using group and time as factors) and Holm-Sidak post hoc tests. Statistical analysis was performed with Sigmaplot 11.0 (Systat a

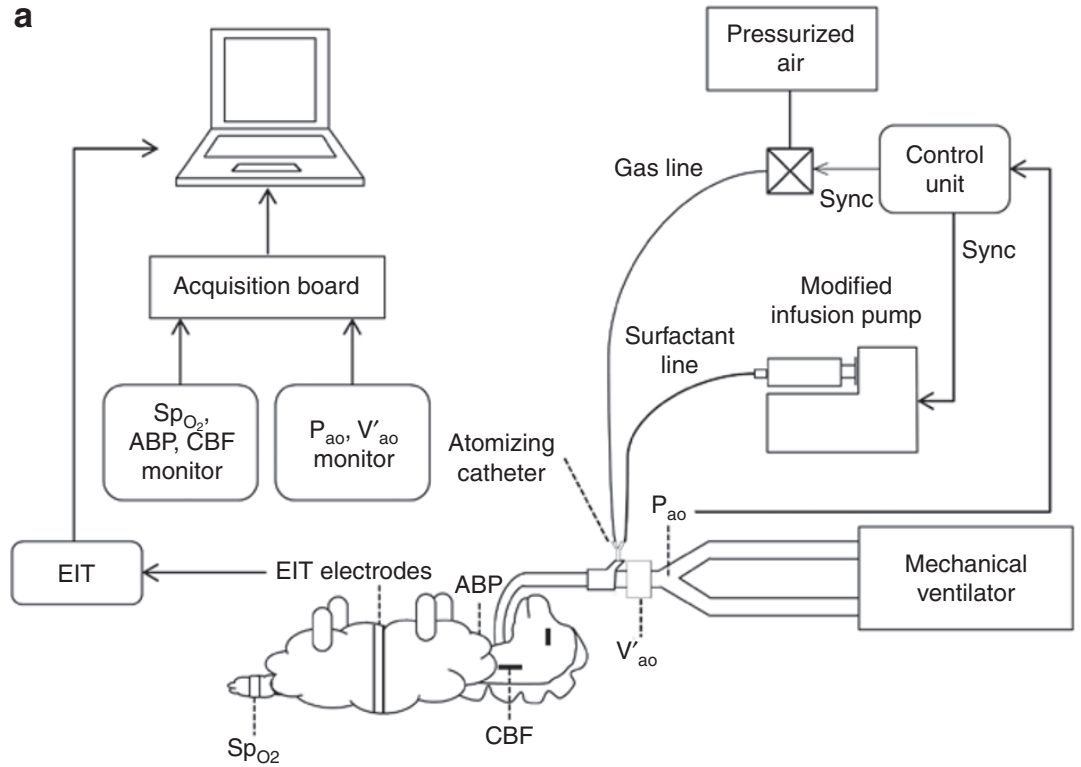

b

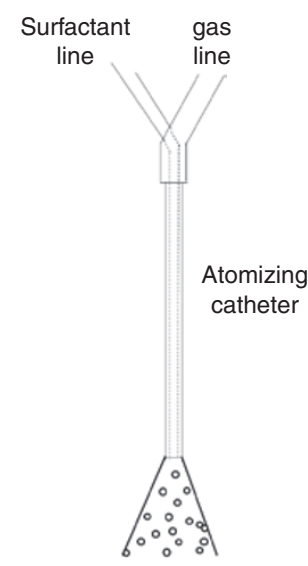

Figure 5. Set-up. Schematic representation of the overall experimental set-up (a) and the atomizing catheter (b). 
Software, San Jose, CA), with a $P$ value $<0.05$ being considered statistically significant.

\section{STATEMENT OF FINANCIAL SUPPORT}

D.G.T. is supported by a National Health and Medical Research Council Clinical Career Development Fellowship (Grant ID 1053889), Canberra, Australia. D.G.T., E.P., D.B., C.E.Z. and M.S. are supported by the Victorian Government Operational Infrastructure Support Program, Melbourne, Australia.

Disclosure: This study was funded by Chiesi Farmaceutici SpA (Parma, Italy), which is the employer of F.B. The animal-derived surfactant Poractant alfa (Curosurf, Chiesi Farmaceutici SpA, Parma, Italy) was also supplied by Chiesi Farmaceutici SpA. Chiesi Farmaceutici S.p.A., employer of F.B., and Politecnico di Milano University, institution of I.M., E.Z. and R.L.D., own patents on the atomization of surfactant.

\section{REFERENCES}

1. Mercier CE, Soll RF. Clinical trials of natural surfactant extract in respiratory distress syndrome. Clin Perinatol 1993;20:711-35.

2. Sandri F, Plavka R, Ancora G, et al.; CURPAP Study Group. Prophylactic or early selective surfactant combined with nCPAP in very preterm infants. Pediatrics 2010;125:e1402-9.

3. Stevens TP, Finer NN, Carlo WA, et al.; SUPPORT Study Group of the Eunice Kennedy Shriver National Institute of Child Health and Human Development Neonatal Research Network. Respiratory outcomes of the surfactant positive pressure and oximetry randomized trial (SUPPORT). J Pediatr 2014;165:240-249.e4.

4. Göpel W, Kribs A, Ziegler A, et al.; German Neonatal Network. Avoidance of mechanical ventilation by surfactant treatment of spontaneously breathing preterm infants (AMV): an open-label, randomised, controlled trial. Lancet 2011:378:1627-34.

5. Dargaville PA, Aiyappan A, De Paoli AG, et al. Minimally-invasive surfactant therapy in preterm infants on continuous positive airway pressure. Arch Dis Child Fetal Neonatal Ed 2013;98:F122-6.

6. Schipper JA, Mohammad GI, van Straaten HL, Koppe JG. The impact of surfactant replacement therapy on cerebral and systemic circulation and lung function. Eur J Pediatr 1997;156:224-7.

7. Murdoch E, Kempley ST. Randomized trial examining cerebral haemodynamics following artificial or animal surfactant. Acta Paediatr 1998;87:411-5.

8. Rey-Santano C, Mielgo VE, Andres L, Ruiz-del-Yerro E, Valls-i-Soler A, Murgia X. Acute and sustained effects of aerosolized vs. bolus surfactant therapy in premature lambs with respiratory distress syndrome. Pediatr Res 2013;73:639-46.

9. Lewis JF, Ikegami M, Jobe AH, Tabor B. Aerosolized surfactant treatment of preterm lambs. J Appl Physiol (1985) 1991;70:869-76.

10. Henry MD, Rebello CM, Ikegami M, Jobe AH, Langenback EG, Davis JM. Ultrasonic nebulized in comparison with instilled surfactant treatment of preterm lambs. Am J Respir Crit Care Med 1996;154:366-75.

11. Ellyett KM, Broadbent RS, Fawcett ER, Campbell AJ. Surfactant aerosol treatment of respiratory distress syndrome in the spontaneously breathing premature rabbit. Pediatr Res 1996;39:953-7.

12. Dijk PH, Heikamp A, Bambang Oetomo S. Surfactant nebulisation prevents the adverse effects of surfactant therapy on blood pressure and cerebral blood flow in rabbits with severe respiratory failure. Intensive Care Med 1997;23:1077-81.

13. Fok TF, al-Essa M, Dolovich M, Rasid F, Kirpalani H. Nebulisation of surfactants in an animal model of neonatal respiratory distress. Arch Dis Child Fetal Neonatal Ed 1998;78:F3-9.

14. Jorch G, Hartl H, Roth B, et al. Surfactant aerosol treatment of respiratory distress syndrome in spontaneously breathing premature infants. Pediatr Pulmonol 1997;24:222-4.

15. Berggren E, Liljedahl M, Winbladh B, et al. Pilot study of nebulized surfactant therapy for neonatal respiratory distress syndrome. Acta Paediatr 2000;89:460-4.

16. Finer NN, Merritt TA, Bernstein G, Job L, Mazela J, Segal R. An open label, pilot study of Aerosurf combined with nCPAP to prevent RDS in preterm neonates. J Aerosol Med Pulm Drug Deliv 2010;23:303-9.
17. Lewis JF, Tabor B, Ikegami M, Jobe AH, Joseph M, Absolom D. Lung function and surfactant distribution in saline-lavaged sheep given instilled vs. nebulized surfactant. J Appl Physiol (1985) 1993;74:1256-64.

18. Lewis J, Ikegami M, Higuchi R, Jobe A, Absolom D. Nebulized vs. instilled exogenous surfactant in an adult lung injury model. J Appl Physiol (1985) 1991;71:1270-6.

19. Li WZ, Chen WM, Kobayashi T. Aerosolized surfactant reverses respiratory failure in lung-lavaged rats. Acta Anaesthesiol Scand 1994;38:82-8.

20. Schermuly R, Schmehl T, Günther A, Grimminger F, Seeger W, Walmrath D. Ultrasonic nebulization for efficient delivery of surfactant in a model of acute lung injury. Impact on gas exchange. Am J Respir Crit Care Med 1997;156:445-53.

21. Wagner MH, Amthauer H, Sonntag J, Drenk F, Eichstädt HW, Obladen M. Endotracheal surfactant atomization: an alternative to bolus instillation? Crit Care Med 2000;28:2540-4.

22. Dellacá RL, Milesi I. Method and system for the administration of a pulmonary surfactant by atomization. European patent 2012016523420120423, WO2013160129 A1, 2013 (patent pending).

23. Leonhardt S, Lachmann B. Electrical impedance tomography: the holy grail of ventilation and perfusion monitoring? Intensive Care Med 2012;38:1917-29.

24. Frerichs I, Dargaville PA, van Genderingen H, Morel DR, Rimensberger PC. Lung volume recruitment after surfactant administration modifies spatial distribution of ventilation. Am J Respir Crit Care Med 2006;174:772-9.

25. Dargaville PA, Rimensberger PC, Frerichs I. Regional tidal ventilation and compliance during a stepwise vital capacity manoeuvre. Intensive Care Med 2010;36:1953-61.

26. Tingay DG, Bhatia R, Schmölzer GM, Wallace MJ, Zahra VA, Davis PG. Effect of sustained inflation vs. stepwise PEEP strategy at birth on gas exchange and lung mechanics in preterm lambs. Pediatr Res 2014;75: 288-94.

27. Tingay DG, Mills JF, Morley CJ, Pellicano A, Dargaville PA. The deflation limb of the pressure-volume relationship in infants during high-frequency ventilation. Am J Respir Crit Care Med 2006;173:414-20.

28. De Jaegere A, van Veenendaal MB, Michiels A, van Kaam AH. Lung recruitment using oxygenation during open lung high-frequency ventilation in preterm infants. Am J Respir Crit Care Med 2006;174:639-45.

29. Miedema M, de Jongh FH, Frerichs I, van Veenendaal MB, van Kaam AH. Changes in lung volume and ventilation during surfactant treatment in ventilated preterm infants. Am J Respir Crit Care Med 2011;184:100-5.

30. Dassieu G, Brochard L, Agudze E, Patkaï J, Janaud JC, Danan C. Continuous tracheal gas insufflation enables a volume reduction strategy in hyaline membrane disease: technical aspects and clinical results. Intensive Care Med 1998;24:1076-82.

31. Frizzola M, Miller TL, Rodriguez ME, et al. High-flow nasal cannula: impact on oxygenation and ventilation in an acute lung injury model. Pediatr Pulmonol 2011;46:67-74.

32. Dysart K, Miller TL, Wolfson MR, Shaffer TH. Research in high flow therapy: mechanisms of action. Respir Med 2009;103:1400-5.

33. Lu KW, Pérez-Gil J, Taeusch H. Kinematic viscosity of therapeutic pulmonary surfactants with added polymers. Biochim Biophys Acta 2009;1788:632-7.

34. Mallol J, Rattray S, Walker G, Cook D, Robertson CF. Aerosol deposition in infants with cystic fibrosis. Pediatr Pulmonol 1996;21:276-81.

35. Zannin E, Ventura ML, Dellacà RL, et al. Optimal mean airway pressure during high-frequency oscillatory ventilation determined by measurement of respiratory system reactance. Pediatr Res 2014;75:493-9.

36. Tingay DG, Wallace MJ, Bhatia R, et al. Surfactant before the first inflation at birth improves spatial distribution of ventilation and reduces lung injury in preterm lambs. J Appl Physiol (1985) 2014;116:251-8.

37. Bhatia R, Schmölzer GM, Davis PG, Tingay DG. Electrical impedance tomography can rapidly detect small pneumothoraces in surfactantdepleted piglets. Intensive Care Med 2012;38:308-15.

38. Tingay DG, Copnell B, Grant CA, Dargaville PA, Dunster KR, Schibler A. The effect of endotracheal suction on regional tidal ventilation and endexpiratory lung volume. Intensive Care Med 2010;36:888-96. 


\section{Articles | Milesiet al.}

39. Tingay DG, Polglase GR, Bhatia R, et al. Pressure-limited sustained inflation vs. gradual tidal inflations for resuscitation in preterm lambs. J Appl Physiol (1985) 2015;118:890-7.

40. Adler A, Amyot R, Guardo R, Bates JH, Berthiaume Y. Monitoring changes in lung air and liquid volumes with electrical impedance tomography. J Appl Physiol (1985) 1997;83:1762-7.

41. Polglase GR, Tingay DG, Bhatia R, et al. Pressure- versus volume-limited sustained inflations at resuscitation of premature newborn lambs. BMC Pediatr 2014;15:14-43.
42. Lauzon AM, Bates JH. Estimation of time-varying respiratory mechanical parameters by recursive least squares. J Appl Physiol (1985) 1991;71:1159-65.

43. Hepponstall JM, Tingay DG, Bhatia R, Loughnan PM, Copnell B. Effect of closed endotracheal tube suction method, catheter size, and post-suction recruitment during high-frequency jet ventilation in an animal model. Pediatr Pulmonol 2012;47:749-56.

44. Marquis F, Coulombe N, Costa R, Gagnon H, Guardo R, Skrobik Y. Electrical impedance tomography's correlation to lung volume is not influenced by anthropometric parameters. J Clin Monit Comput 2006;20:201-7. 